\title{
Decentering the Intervention Experts: Ethnographic Peace Research and Policy Engagement
}

Gearoid Millar

Institute for Conflict, Transition, and Peace Research

University of Aberdeen

\begin{abstract}
:
The failures of peace interventions are often associated with their exogenously conceived and technocratic nature, which discount complexity within and diversity between post-conflict contexts. In response, scholars have resorted to concepts of empowerment, resistance, hybridity, and friction to refocus post-conflict policymaking away from 'top-down' and towards 'bottom-up' processes. Any such efforts, however, require that policymakers understand the local drivers and everyday experiences of peace interventions across a range of cases; a task for which the current tools of the intervention experts have proven unsuited. This paper, therefore, proposes an Ethnographic Peace Research (EPR) agenda which would provide access for and influence to the 'peace kept' and decenter the intervention experts in peacebuilding policy. In its effort to influence policy, however, an EPR agenda faces substantial challenges. These include, among others; the failure of academics to communicate clearly to nonacademic audiences, the ideological biases of policymakers, and the relentless simplification of complexity. However, as will be discussed and evidenced using a variety of cases below, an EPR approach also has a number of strengths which can enhance its relevance for policy, serve to decenter the intervention experts, and develop a credible alternative bottom-up approach to policymaking in postconflict states.
\end{abstract}

\section{Keywords:}

Peace Research; Peacebuilding Policy; Ethnography; Methodology; Evaluation; Bottom-Up 


\section{Introduction}

Academics studying post-conflict interventions are under substantial pressure to make their research and findings pertinent to policymakers and practitioners. They are encouraged to add recommendations to articles, to incorporate stakeholders into new research projects, and to develop 'pathways to impact' via policy reports and practitioner workshops. However, while well intended, decades of research regarding 'knowledge utilization' theory and dynamics indicates that the direct transfer of academic knowledge to policy has actually been quite limited. There are a number of reasons for this, including the failure of academics to communicate clearly to non-academic audiences, the ideological biases of policymakers, and the need among policymakers to simplify complexity. These findings must be acknowledged by any academics hoping to influence policy. Indeed, in peace, security, and development studies, where the international and cross-cultural dimensions inherently imply additional complexity, such barriers are even more concerning.

As a result, scholars hoping to impact policy must a) understand the limitations of knowledge transfer as discussed in the existing 'knowledge utilization' literature, b) develop methodologies to collect data and provide insight to overcome those limitations, and c) actively communicate their findings to policy and practitioner communities to maximize the impact of their findings. While the third of these (engagement with policymakers) is becoming more common, the success of communication is reliant on the first two being achieved, and this is where academia has fallen short. Indeed, academics studying post-conflict interventions are largely unaware of the knowledge utilization literature, have little understanding of what these barriers may be, and so do not usually consider the strengths of their research approaches to overcome them. This paper, therefore, accomplishes the first task (a), and proposes an Ethnographic Peace Research (EPR) approach which might accomplish the second (b).

The remainder of this article is divided into four sections. The first introduces both the dominant mode of peace interventions in the post-Cold War period and the prominent critiques which have led to recent calls for more grounded or ethnographic research in post-conflict contexts. The second reviews the 
knowledge utilization literature, focusing specifically on the many barriers to knowledge transfer identified by scholars in the fields of international peace, security, and development. The third introduces the EPR approach and describes, with reference to a variety of studies, why this approach is particularly suited to overcome many of the recognized barriers to knowledge utilization. The concluding section summarizes the argument and reflects on the challenges to an EPR agenda and its potential impact on policy. While EPR is not a panacea, this paper argues that it is certainly among the best options for decenting the intervention experts in post-conflict policy.

\section{Liberal peace and its current critiques}

In the post-Cold War period ever more supranational, national, and non-governmental organizations (NGOs) have committed time, resources, and manpower to building the 'liberal peace' based on the three pillars of democracy, free markets, and the rule of law (Doyle, 2005). This model is related to the long established 'Wilsonian' liberal peace (Paris, 2004: 6), which was originally theorized as a mechanism ensuring stability between interdependent states (Helbich, 1967-1968), but which, in the post-Cold War period, also became the primary means of ensuring domestic peace within post-conflict states. As such, it is an extension of the Western derived norms of governmentality and authority evident in theories such as the 'democratic peace' (Russet, 1994), but applied in a diverse array of contexts around the world. In the post-Cold War period this 'liberal orthodoxy' came to be 'treated as so compellingly commonsensical' as to be 'almost beyond the reach of questioning' (Selby, 2011: 19)

Further, while initially applied in response to the end of the proxy wars (Central America), conflicts that erupted after the dissolution of the Soviet Union (the former Yugoslavia), and the collapse of weak states in the 1990s (West Africa), the liberal peace quickly became institutionalized, normalized, and formalized as best-practice. Post-conflict intervention became a professionalized process (Sending, 2009: 3), dominated by 'tool-kit' and 'cookie-cutter' approaches (Shaw, 2005; Call and Cousens, 2008: 14; Donais, 2009: 23; UN 2012). It became accepted within the institutions that control intervention 
policy that technocratic mechanisms could solve post-conflict dilemmas (Goetschel and Hagmann, 2009: 66; Mac Ginty, 2010: 408), and the power to make post-conflict decisions was distributed not to local actors within post-conflict states, but to technocrats within those institutions (Clark, 2011; Teethling, 2011; Autesserre, 2014: 116); the intervention experts.

However, the increase in interventionary projects and the concentration of intervention authority was paralleled by academic assessment of such activity, much of which was highly critical (see for example Paris, 2004; Chandler, 2006; Mac Ginty, 2011). Negative findings prompted concern over the lack of 'local ownership' and 'buy-in' to peacebuilding mechanisms and highlighted the potential divergence between Western norms of legitimate authority foundational to the liberal peace model and alternative local norms unrecognized by intervention experts (Shaw, 2005; Franks and Richmond, 2008; Sending, 2009; Donais, 2009; Shaw, Waldord \& Hazan, 2010; Millar, 2010, 2013; Richmond, 2012). In response, scholars turned to concepts of the everyday (Richmond, 2009; Richmond and Mitchell, 2011; Autesserre, 2014), emancipation (Richmond, 2006; Theissen, 2011; Brett and Malagon, 2013; Leonardsson and Rudd, 2015), resistance (Mac Ginty, 2011; Kappler and Richmond, 2011), hybridity (Mac Ginty, 2010; Belloni, 2012; Millar, 2014b), and friction (Millar, Van der Lijn and Verkoren, 2013; Björkdahl and Höglund, 2013; Björkdahl et al, 2016) to theorize how peace might be built not for those living in post-conflict contexts by intervention experts, but through interaction and exchange.

These contributions recognize that interventions occur in complex social, economic, cultural and political environments and that the resulting 'hybrid peace' outcomes involve the 'mixing and melding of institutions, practices, rituals, and concepts generated through the interaction of coexisting, competing or complementary structures and norms' (Millar, 2014b: 503). They emphasize the complex nature of postconflict contexts and the limited ability of intervention experts to control the outcomes of their action. This point is of central importance here as the term 'complex' implies specific characteristics about the local context which function to make interventions subject to unpredictable feedback dynamics generative of emergent properties (see Miller and Page, 2007; De Coning, 2013; Coetzee, 2013). In more plain 
terms, the constant interplay of social, cultural, political and economic dynamics - all commonly foreign to intervention experts working in unfamiliar settings - make accurate prediction of intervention impacts impossible. As a result, well intentioned efforts to formulate and implement policy often give rise to unexpected and even conflict-promoting effects. However, while avoiding unexpected outcomes is not possible, by understanding such local dynamics more nuance and sensitivity can be incorporated into post-conflict policies. While the track record of knowledge utilization in intervention policy is quite bad as will now be discussed - accepting complexity and deploying an EPR approach may be one way to improve this.

\section{Knowledge utilization for intervention policy}

Many lament the limited influence of academics in intervention policy, but few scholars have examined the problem systematically. Those who have, however, point to a worrying number of barriers limiting the policy impact of peace, security, and development research. An early contribution from Anatol Rapoport, for example, identified the lack of institutions tasked with carrying out peace policies as one key barrier to policy impact. In Rapoport's opinion this limitation meant that there could be no applied peace research (1970: 282). Years later, and focusing specifically on the limited policy impact of quantitative peace research findings, Andrew Mack identified eight additional barriers to knowledge utilization (2002). These included the failure of academics to communicate clearly, the focus on international instead of intrastate conflicts, the limited understanding of econometric analysis among policymakers, the tendency for policymakers to nullify generalized findings via single counter examples, the diversity of incompatible datasets, the lack of reliable (or any) measures for important dynamics of conflict and peace, the lack of interdisciplinary research, and inconsistencies between research findings regarding the causes of conflict (ibid: 516-520). Mack argued that until peace research can overcome each of these barriers 'policymakers will remain reluctant to embrace findings and prescriptions which they either do not understand or which appear to contradict each other' (ibid: 254). 
On the other hand, some contemporary scholars do believe that peace research has impacted policy. Paffenholz and Reychler argue that the 'Aid for Peace' approach has contributed to more positive peacebuilding policy in individual cases (2005), while Richmond argues that key concepts in the critical peacebuilding literature - such as 'local empowerment' - have been integrated into the policy documents and core mission of the UN (2012: 356-357). However, while Paris agrees that peace research concepts such as 'peacebuilding', 'statebuilding', 'bottom-up', and 'hybridity' have been incorporated into policy documents (2011: 64-65), in one of the few articles among peace scholars exploring the existing knowledge utilization literature, he also identifies three additional barriers to knowledge transfer in peace research not identified already by Mack: the limited time for reading among policymakers, the potential for research findings to be manipulated or distorted by ideologically biased policymakers, and the potential for unreliable findings to circulate and pervade policy just as quickly as reliable findings (ibid). Further, while agreeing with Richmond that some concepts have been incorporated into policy, he also notes that they can become so powerful as to be hard to dislodge even if later disproven (ibid: 63). Indeed, as has been argued before regarding 'ownership' (Donais, 2012: 6), 'hybridity' (Millar, 2014b: 502), and 'empowerment' (Sukarieh and Tannock, 2008), such concepts can be used to serve the interests of biased policymakers and the institutions they represent.

These findings are consistent with those of a study into the utilization of statebuilding research by the United Kingdom's Department for International Development (DfID), which similarly found indirect conceptual influence on policy via 'collective absorption' (Barakat, Waldman and Varisco, 2014: 15), but which also highlighted various barriers. These included the tendency of policymakers to incorporate only findings that justified their established position (ibid: 8), a bunker mentality among policymakers that promoted their reliance on paid consultants for research (ibid: 9), the longer time needed for academic research (Varisco, 2014: 90), pressure for results among policymakers (ibid: 113), the challenge of synthesizing and understanding too much research (ibid: 114), and a lack of local cultural insight (ibid: 
114). There is, therefore, a long list of barriers to knowledge utilization, which can be disaggregated into five categories; institutional, ideological, cultural, practical, and academic (see Figure 1).

\section{Figure 1: Key Barriers to Knowledge Utilization in Intervention Policy}

\begin{tabular}{l} 
Institutional \\
Lack of Institutions tasked with implementing peace \\
Constant pressure for results among policymakers \\
Unreliable findings can pervade policy just as fast as reliable ones \\
Ideological \\
Manipulation of findings by ideologically biased policymakers \\
Incorporation only of findings that support established positions \\
Cultural \\
Little understanding of econometric analysis \\
Single case nullification of generalized findings \\
Bunker mentality promoting use of paid consultants \\
Practical \\
Failure of communication \\
Lack of useful local cultural insight in completed research \\
Challenge of synthesis and understanding too much research \\
No time for reading among policymakers \\
Need for extensive time for academic research \\
Academic \\
Focus on International not intra-state conflicts \\
Diversity of incompatible datasets \\
Lack of reliable measures for important conflict and peace dynamics \\
Lack of interdisciplinary research \\
Inconsistencies between key findings on the causes of conflict \\
\hline
\end{tabular}

However, these barriers are far from unique to post-conflict policy. They are found also in the more general 'knowledge utilization' literature. This field was rooted initially in a linear model 'based on assumptions of rational and instrumental behavior' in which policymakers would make decisions and then all actors in the policy implementation chain would carry out the decisions made above; good policy would thus result in correct implementation and, eventually, predictable outcomes (Keeley and Scoones, 1999: 4). However, this overly simplistic linear approach was later supplanted by Lindblom's idea of ‘incrementalism' or 'muddling through' (1979). 'Muddling through' recognizes the non-rational and 
contingent nature of policy as dependent on actors and decisions not only at the highest levels of policymaking, but along the entire chain of policy implementation. This model resists the notion of longterm policy planning (Lindblom, 1979; 518), and, in Elmore's formulation (1979-80), even relocates power from the higher levels of authority to those actors closer to the target of policy (we will return to this later).

Another alternative to the linear model adds even further nuance in considering not only nonrational actors and decisions along the chain of policy implementation, but the 'relationship between knowledge, power and policy' more broadly. This 'Foucauldian' model is most applicable to the case of international intervention, as it views policies themselves as " "political technologies", enmeshed in the relations of power between citizens, experts and political authorities' (Keeley and Scoones, 1999: 5). It demands that we focus not only on rational decisions (the linear model), or even on non-rational decisions and responses by policy actors (the incrementalist model), but on the 'legitimating discourse' ... 'the associated metaphors, labels and symbols of scientific authority' which are normalized and so internalized unknowingly by all policy actors (ibid: 5).

For this paper, the most pertinent difference between these three models is the level of complexity acknowledged in each. Elmore, for example, argues that the linear model is inherently flawed for understanding any policy formulation, but only more so as the complexity of the policy environment increases and more actors, with a diversity of incentives, become relevant to implementation (1979/80: 605). Haas argues that 'complexity tests the limits of human understanding' and that increasing uncertainty in the policy environment leaves policymakers unable to assess even the differing risks and benefits of policy options (1992: 14-16). Crew and Young too focus on the way that complexity compounds the problems of knowledge utilization, noting that policymakers have an urge to simplify which limits their ability to interpret and use research (2002: vi). Keeley and Scoones capture this problem well, noting that the linear model assumes a direct and powerful hierarchy, a predictable bureaucracy, and so top-town mechanisms of control. They argue that in linear models the need to 
universalize knowledge conceals complexity to generate an 'artificial certainty' (1999: 11), which functions to maintain the hope of prediction and control. A Foucauldian model, on the other hand, assumes complex relationships and unpredictable practices due to the influence of 'street level bureaucrats' and the vagaries of 'internal institutional frictions' (ibid: 16). Once complexity is acknowledged, they argue, artificial certainty collapses and the contingent nature of policy implementation becomes clear. In this way, complexity itself is one more barrier to predictable policy impact.

These authors make plain that the more complex the policy environment, the less a linear model can be applied and the more a Foucauldian model must be considered. Given the recognized complexity of post-conflict contexts, it should be quite clear that this third model would maintain and scholars of post-conflict intervention should have limited trust in the ability of their research findings to influence intervention policy in a predictable manner. Unfortunately, few scholars of intervention have read this literature and these lessons have not been learned. Indeed, academics do often think that knowledge can influence policy directly and predictably. In addition, the structures of funding and support within which academics work assume this linear model and apply pressure on academics to work towards policy 'impact'. But if we take seriously the various barriers described above, and the recognition of complexity in contexts of post-conflict intervention, then we must design and carry out research specifically to overcome these barriers. While certainly not a panacea, EPR is well suited to accomplish this.

\section{Ethnographic peace research}

Millar previously outlined 'an ethnographic approach to peacebuilding', which provided guidance for researchers conducting ethnographic evaluations of individual post-conflict mechanisms (2014a). He did not, however, describe the kind of broad research agenda that might achieve the robust policy impact we are concerned with here. A broader research agenda is necessary because, as argued by Barakat, Waldman, and Varisco, scholars hoping to impact policy must contribute to a "“critical mass" of robust, 
credible and mutually supporting evidence' which can 'penetrate policy circles, shift thinking and catalyse policy change' over time (2014: 23). A collection of individual case studies cannot provide such a critical mass. Indeed, while there have at this point been quite a few ethnographic studies of individual post-conflict interventions (many of which will be discussed below), these have not resulted in substantive change in post-conflict policy.

So, what is EPR and how would an EPR agenda be formed? While it is not always ethnography in the classic Anthropological sense, all such research seeks to understand and explain how and why certain phenomena or certain experiences emerge in relation to violence, conflict, transition, or peace via ‘thick description' and an engaged ‘ethnographic imagination’ (Millar 2018a: 259). Such research is characterized by reflexivity on the part of the researcher, and by a diversity of methods that commonly include participant observation, semi-structured interviews, and extensive qualitative field-notes, among many others (ibid). It is such research that I call EPR, and it is only by promoting, supporting, funding, connecting and collating such research that a robust EPR agenda can be realized. In what follows I will first indicate how EPR can overcome some of the specific barriers identified above, before then illustrating how these various strengths serve also to overcome the more fundamental problem of complexity in post-conflict policy.

\section{Lack of cultural insight and contextual relevance}

First, and perhaps most obviously, an EPR approach can provide the cultural insight and contextual relevance noted as missing from many studies by Varisco. While most scholars today recognize the contextual and cultural differences between post-conflict contexts, many studies fail to appreciate the radical differences in expectations and experiences of post-conflict interventions that this will generate. Instead, in many quantitative studies a proxy measure such as religion or language is used to measure 'culture', and little effort is made at real comprehension. Instead, an array of evaluative research processes concerned with tick-boxes, check-lists, and quick field visits amounting to a handful of days in 
country have become common (Millar, 2014a; 18). No widely applied evaluative process used today demands more engagement with either the ethnographic literature or first-hand experience with the context of the intervention under assessment.

An EPR approach turns this situation on its head through engagement with the ethnographic literature regarding the society being intervened upon, and long-term engagement in the context itself (see Millar 2018b). This has been evidenced in the work of many scholars over the years, but perhaps most clearly by those with long-term field experience in a society even before violence, conflict, or war occurred. This is the case, for example, with the work of Rosalind Shaw in Sierra Leone. Shaw had worked in Sierra Leone for more than a decade before war erupted there in 1991, and her writings on the post-conflict intervention mechanisms after it ended in 2002 evidence both a comprehensive understanding of the literature and her own experiences of local social, cultural, and religious dynamics $(2005,2007)$. Her knowledge of the culture and the context both greatly enhanced the insight she could provide regarding the local experience of the post-conflict interventions, and the relevance of her suggestions for post-conflict reconciliation processes in such contexts (see Shaw 2005). This exemplifies how EPR can overcome the barrier to policy impact posed by a lack of cultural insight and contextual relevance.

\section{Lack of reliable measures}

Building on this first strength, an EPR approach could also work to overcome the barrier identified by Mack regarding the lack of reliable (or sometimes any) measures for important conflict dynamics. Through a deeper knowledge and understanding of the local culture and context new and innovative measures of important peace and conflict dynamics might be developed. Mac Ginty and Firchow's 'Everyday Peace Indicators' project (2016) is an effort to develop exactly such locally derived and substantive measures of conflict and peace dynamics in post-conflict contexts. Instead of assuming that externally derived measures are appropriate in every context, this work attempts to illicit from local actors 
within conflict affected contexts very specific and contextually appropriate indicators by which to assess the state of peace. As evidenced so convincingly by Engle Merry and Wood, significant 'cultural work' is necessary to develop locally derived and reliable measures (2015: 206), even for concepts that seem to have obvious meanings to an international audience such as 'security,' 'justice,' or 'rights.' Such efforts to define more contextually relevant measures indicate the potential of a broader EPR agenda to generate more locally pertinent and contextually specific measures of conflict and peace dynamics.

It is clear, of course, that such measures will not be what a quantitative scholar such as Mack would hope for, in that they will not be universally applicable and comparable across contexts. But, as argued by Engle Merry and Wood, such quantitative measures are not themselves inherently reliable. Indeed, in Elmore's 'backward-mapping' approach we see the considerable limitations to generalized knowledge itself in intervention policies, as the real power to either implement or derail policy multiplies as proximity to the target of policy increases (1979-80). The further we generalize knowledge, the less it is pertinent to the micro-dynamics of intervention in any given context and, to return to Mack's concern, the less reliable it is. An EPR approach, on the other hand, focuses attention on the local, on the micro, and on 'the everyday'. Thus, at least potentially, providing reliable and contextually specific measures.

\section{Lack of practical recommendations}

Third, and again building on the above, the contextualized knowledge developed in EPR projects can generate instructive findings and practical recommendations for policymakers working in specific contexts. This is exemplified, for example, in the work of Simon Robins in Timor-Leste, who utilized ethnographic methods to engage with victims of the violence in Timor-Leste, to inquire about their needs, and to ask whether those were met by the transitional justice processes in that society (2012). In doing so Robins' study found that victims on the ground would prefer economic support and proper memorials for the missing and the dead; a clear recommendation for ongoing transitional justice efforts in that case. In other work, Gearoid Millar has found great diversity in what Sierra Leonean's need or want from post- 
conflict processes. He notes specifically the difference between what privileged elites feel is necessary and what the largely impoverished non-elite require in the same context $(2010,2017)$. Such studies, therefore, can highlight to policymakers the specific needs within post-conflict contexts.

As discussed above, there is great diversity between but also within most contemporary postconflict states, and the intervention experts - hired, as Autesserre has shown, not for any contextual, cultural or linguistic knowledge but for their technocratic expertise - rarely have much understanding of that local diversity (2014). The best policy advice they can be provided, and that which is most needed, will therefore be that which can assist them in making their technocratic skills pertinent to the local context. As such, EPR can instruct policymakers on how to make national level interventions pertinent to those living in the local contexts. But this does not mean that EPR is only pertinent to policy decisions at the micro-level. It simply means that its findings will become more practical, direct, or instructive at the most local level among the 'street level bureaucrats' (where the power lies to implement or disrupt policy) (Keeley and Scoones, 1999: 16; Elmore 1979-80), and more generalized and less directly applicable the higher up the chain of 'authority' we travel.

\section{Lack of clear communication to non-academic audiences}

Even given the three clear benefits to EPR noted thus far, as different cultures and cultural difference itself can be difficult to understand, we must also consider to what extent EPR could overcome a fourth barrier to knowledge utilization - the failure of academics to clearly communicate with policymakers. Will the very nuance and complexity uncovered in EPR not be more difficult to communicate to policy audiences than simplified measures? This is a difficult question, but even in its acceptance of difference and complexity an EPR agenda should still have a good chance to overcome the barriers of communication (certainly just as much as econometric research). This is because much of the data collected during EPR is in the form of life histories, narratives, biographies, images, and field-notes. While such text heavy data can certainly be presented badly at times, it can also provide the raw material 
for alternative forms of dissemination and communication (exhibits, films, blogs, performances, etc.), as well as easily accessible policy documents and presentations with accompanying illustrations, examples, biographies and vignettes, as promoted by Keeley and Scoones (2014: 27). If used appropriately by skilled researchers, this data can allow for clear and convincing communication.

A number of projects that have utilized Photography for peace research, for example, exemplify both creative approaches to engaging different communities in research activities as well as generating accessible research outputs in the form of engaging visual data. This is the case with Valentina Baú's work in Kenya (2015), which both highlights how such visual methods have been used in the past for action and advocacy based research and how they can also generate positive change among the research participants. In this project a group of nine young people from diverse tribal backgrounds who had experienced conflict within Kenya's Rift Valley came together in workshop settings to present pictures they took of images that represented, to them, the post-election violence of 2007/2008 and the progress towards and remaining barriers to peace in the wake of this conflict (ibid: 79-80). When combined with the narratives participants formed to explain their choices of images, this project both inspired new perspectives among the group of young people involved, and generated images and narratives regarding the conflict which could (with the agreement of the participants of course) potentially be utilized for policy impact purposes at a later point, even though policymakers were not involved in the workshops themselves.

Another example is found in the work of Camellia Webb-Gannon and her colleagues at the University of Sydney, whose ethnographic research 'involved collaboratively producing the Biak Massacre Citizen's Tribunal', which was then covered by the television news (2017: 29). Based on extensive prior ethnographic work, Webb-Gannon argues that ethnography aimed at policy influence can be most transformational when it is 'creative and unexpected', when it generates materials 'that do not stick to traditional academic formats', and when they 'involve and lobby powerful individuals or bodies who have the ability to enforce structural change' (2017: 32). Such examples evidence the power of EPR 
not only to understand local experiences of peace and conflict, but to generate engaging ways to communicate those experiences to policy audiences. That is not to say, of course, that all EPR produces such data, but even EPR based academic articles can be easier to read and more accessible than the academic products of quantitative studies and they often incorporate many illustrative examples and vignettes which could be reused and easily disseminated to policymakers in policy documents and briefs. As a result, while there are challenges to the communication of EPR findings to policymakers, the form of data common in EPR studies is also very valuable for clear communication.

\section{Lack of personal engagement with policymakers}

An additional barrier that may be overcome to some extent by EPR scholars is the lack of personal engagement with policymakers. As argued by Varisco, networks and personal relationships between researchers and policymakers are key to successful knowledge utilization (2014: 108). This is a point further highlighted by Crewe and Young, who include as one of their three main findings that 'research is used more effectively in policy processes if researchers and policy makers share particular kind [sic] of networks' (2002: 18). It is of course perfectly possible for researchers of almost any methodological persuasion to interact with high level policymakers in New York, London, Washington D.C. or Brussels, and accomplish the kind of long-term indirect influence described by Paris (2011: 64-65) and Barakat, Waldman and Varisco (2014: 15). However, as discussed, the linear model of knowledge utilization (which locates the power in such metropolitan centers) is not applicable in complex contexts and we must instead see the primary power to either implement or derail policy as located with those on the ground. As a result, if the goal is to influence policy directly then the kinds of relationships academics could best use for knowledge utilization are not with high level policymakers, but with policy actors on the ground; and most academic researchers spend very little time on the ground.

However, an EPR approach often requires researchers to engage with exactly those local actors who wield the power of implementation. Jason MacLeod's work among the various independence groups 
in West Papua (2015) is one example of such close relationships with policy actors on the ground, as is Autesserre's long-term engagement with UN peacekeepers in the Democratic Republic of Congo (2014). Indeed, in their study of anthropologist's engagement with policymakers in humanitarian relief, Abromowitz, Marten and Panter-Brick found that $20 \%$ of respondents reported affiliations with local organizations while conducting their research (2014: 4). EPR scholars spend months on the ground, conducting participant observation among practitioners, interviewing both policymakers and 'beneficiaries', moderating focus groups, etc. As a result, they often form the necessary personal relationships with on the ground policy actors and can communicate research findings to them. Indeed, EPR may be particularly useful in overcoming this barrier as it is open not only to engaging actors on the ground, but to incorporating them into the research process as active partners, as was the case for WebbGannon (2017).

\section{Avoiding distortion or selective acceptance of knowledge utilization}

This leads to two of the more problematic findings within the knowledge utilization literature; the tendency for policymakers to selectively accept research findings, picking up and promoting those which best justify ideological positions they already hold or decisions they have already made (Barakat, Waldman and Varisco, 2014: 8), and the tendency for policymakers to distort or manipulate findings to meet their own needs (Paris, 2011: 60). Both point to the same problem of course; that findings, once published, can be used by policymakers as they see fit, free of the nuances or ethical intentions of the researchers who developed them. This is the core of David Chandler's critique of the local turn, for example - which he argues has provided an opening for powerful global institutions to target 'society directly' (2013: 22) - and is at the heart of broader concerns regarding the utilization of ethnographic data by colonial, military, or political actors (Pels and Salemink, 1994; Hirsch, 2005; Albro, 2010).

Research findings resulting from an EPR agenda are clearly not immune to these troubles and the ethical questions deriving from them should be foremost in the minds of scholars seeking to conduct EPR, 
and certainly among those seeking to engage with policymakers via EPR. But as has been noted, for example, by Rosemary McGee in her reflections on the use of ethnography within Rapid Appraisal, while ethnography for policy purposes can run the risk of being an extractive enterprise, with sufficient preparation, knowledge of the local setting, and sensitivity, it can avoid this threat (1997). Indeed, in their reflections on contemporary ethnography Holmes and Marcus have argued that an engaged and collaborative process embraces local knowledge, agency, creativity and practice, without becoming strictly extractive (2008). Indeed, they argue that contemporary collaborative ethnography triggers mutual appropriations (ibid: 88). Another form of EPR that may reach this end is one which seeks to privilege indigenous voices and counter historical marginalization, as called for by Linda Tuhiwai Smith (1999). Any such process should clearly be encouraged as this may serve as a form of resistance against the imposition of power via policy. Similarly, research seeking to generate knowledge collaboratively with participants, and which fully integrates 'subjects' into the research process - as is evident, for example, in Collins and Watson (2018) - should be promoted. In short, we are right to be concerned about the potential for ethnographic data to be instrumentalized and turned against those whom scholars seek to help, and it is incumbent up on EPR scholars to be aware of and defend against such instrumentalization.

However, two aspects of EPR provide some defence. First, consistent with Crewe and Young's suggestion for researchers to 'map out their legitimacy chains through systems of accountability' (2002: vii), EPR provides a basis for scholars to counter the distortions of policymakers via legitimacy chains rooted in the personal relationship to study participants foundational to ethnographic work. Such relationships are exemplified by the work of scholars such as Kimberly Theidon in Peru (2013) or Michael Jackson in Sierra Leone (2004), whose work evidences close relationships spanning decades. Such close association with local individuals and communities provide scholars with some grounds to resist illegitimate uses of their data and findings. Second, the reversal of the power/proximity model and the changing specificity of recommendations from the general (higher up where policymakers are weak) to the specific (on the ground where policy actors are strong), means that it becomes less likely that 
policymakers will have much to distort or use to their advantage at higher levels. An EPR agenda could direct only the most broad and probably quite anodyne recommendations towards high level policymakers, probably providing little to be distorted for maleficent purposes on a grand scale.

\section{Complexity}

And it is this reversal of the power/proximity model in the more developed knowledge utilization literature - that which acknowledges and accepts the complexity of the policy environment - which most firmly promotes an EPR agenda as a fruitful avenue towards post-conflict scholarship with the aim of decentering the intervention experts. This reversal relocates the source of useful information from the international to the 'local' and, like Elmore's 'backward mapping' approach, justifies the privileging of indigenous knowledge. As Elmore describes, 'the problem-solving ability of complex systems depends not on hierarchical control but on maximizing discretion at the point where the problem is most immediate' (1979-80: 605). Formal authority travels from the top-down but, as is now firmly established, cannot have predictable outcomes on the ground. Informal authority, on the other hand, 'derives from expertise, skill, and proximity' and 'travels in the opposite direction', from the bottom-up (ibid: 606). It is, therefore, only by empowering those at the coalface that we can harness this expertise. Indeed, Elmore correctly observes that 'one of the great ironies of increased attention to implementation is that the harder we try, using conventional tools of hierarchical control, the less likely we are to achieve' (ibid: 608).

In short, to 'achieve' (or succeed) we must engage, communicate, cooperate with, and understand individuals and communities in post-conflict societies. It is only by understanding local experiences of conflict and peace, and concepts of recovery and reconciliation (as evidenced in the various studies cited above), by facilitating or supporting local processes of conflict management or transformation, and, where appropriate, by amplifying the voice of such communities, that we can 'achieve' the goal of supporting peace. At this point there is little reason to believe that international intervention experts have the answers to the problems of peacebuilding in complex post-conflict contexts, and while there are certainly concerns 
with romanticizing the local and with empowering potentially non-liberal local elites (Paffenholz, 2015: 858), if one understands the lessons of the knowledge utilization literature and accepts that the power lies with those who implement and not those who make policy, then it seems an EPR agenda incorporates many of the right tools to best impact post-conflict intervention policy and practice. This is, of course, primarily by decentering the intervention 'experts'.

\section{Conclusion}

This paper has made a relatively simple argument connecting three elements. First, I provided a brief review of the post-conflict peacebuilding literature, exploring specifically the concept of the 'liberal peace' and its various critiques. These critiques generally identify the failures of post-conflict interventions with the universalized liberal model, point to the lack of local ownership and buy-in, and, more recently attempt to describe the complex nature of post-conflict contexts and the contingent or unpredictable nature of post-conflict intervention. Second, I explored the knowledge utilization literature, with a particular focus on the work of scholars within peace, security, and development studies who have examined the transfer of intervention research to policy. This review, which also briefly discussed knowledge utilization theory, identified a series of barriers to knowledge utilization pertinent to intervention policy and identified the complexity of the policy environment as a key multiplier of knowledge utilization problems. Finally, in the last section I discussed EPR as a fitting approach to overcome many of these barriers, to decenter the intervention experts, and to refocus on local policy actors and the experiences of individuals and communities targeted by peace interventions.

I certainly do not want to give the impression that EPR is a panacea, that such research can easily solve the problems of contemporary post-conflict policy formation, or that it is without risks both for the researcher and the researched. Indeed, EPR is not for everyone, faces quite substantial challenges in any efforts to impact policy, and bears all the same risks and limitations so commonly identified with ethnography generally. Both policymakers and non-ethnographically focused academic audiences often 
question the generalizability of ethnographic data; inherently local and specific as it is. They doubt the usefulness of local cultural knowledge and resist funding and supporting such research; whether in the form of training young researchers, funding research projects, or publishing ethnographic work. On the other side, anthropologists and ethnographers within cognate disciplines are ambivalent about engaging with policymakers and risking the instrumentalization of local knowledge for unintended purposes, as occurred previously during the colonial period and in Vietnam and Iraq. There are very real fears about the ends to which knowledge might be deployed once it has left the confines of academia.

While these are real and valid concerns (on both sides), they do not undermine the contribution a robust EPR agenda can make to overcoming the stagnation in post-conflict policy formation. Indeed, all parties at least rhetorically recognize the need for more locally owned and driven processes to ensure sustainable peace, security and development in post-conflict contexts. Most recognize also that locally specific cultural, social, political and economic dynamics are central to how peace, security and development are conceived, envisioned, and, potentially, may be realized. With such recognition should come also an acknowledgement that local knowledge is valuable for policy formation, and specifically for a model of policy formation that values recommendations on a specificity spectrum from highly localized and specific to highly generalized and therefore abstract. There is very good reason for, and should always be, active vigilance against the appropriation and instrumentalization of ethnographic data, but no more so than there should be of quantitative data (an issue often overlooked completely).

The same is true for biases that may interfere in ethnographic research; the manner in which gender, age, class, or ethnicity may influence the researcher's perspective on a question or their access to and engagement with a community. Yes, of course such issues are challenging for anyone seeking to conduct ethnographic peace research. But no more so than is true for quantitative research, for national level qualitative research among elites, or for purely documentary based analysis of peace agreements, laws, or institutional mechanisms of intervention. Indeed, if anything the ethnographic tradition has at least the tools within it to recognize such biases in the form of the well-developed norm of researcher 
reflexivity; a norm largely absent from other research traditions. In short, while these various challenges remain, they are no more insurmountable for an EPR agenda than for any other research tradition and, indeed, may be less so. While the focus of this special issue is on Decentering the Study of International Interventions, and this paper clearly addresses that focus, it must also be recognized that decentering the study is key to decentering the policy and practice of international interventions. An EPR agenda, as I have shown, can decenter the intervention experts and relocate some influence over peace intervention policy to the 'targets' or 'beneficiaries' of peace intervention.

\section{References}

Abromowitz S, Marten M and Panter-Brick C (2014) Medical humanitarianism: Anthropologists speak out on policy and practice. Medical Anthropology Quarterly 29(1): 1-23.

Albro R (2010) Anthropology and the military: AFRICOM, 'culture' and the future of Human Terrain Analysis. Anthropology Today 26(1): 22-24.

Autesserre S (2014) Peacebuilders: An Ethnography of International Intervention. New York, NY: Cambridge University Press.

Barakat S, Waldman T and Varisco A (2014) Understanding Influence: Summary Report for DfID. https://www.gov.uk/dfid-research-outputs/understanding-influence-summary-report-for-dfid

Baú V (2015) Participatory photography for peace: Using images to open up dialogue after violence. Journal of Peacebuilding \& Development 10(3): 74-88.

Belloni R (2012) Hybrid peace governance: Its emergence and significance. Global Governance 18(1): 21-38.

Björkdahl A and Höglund K (2013) Precarious peacebuilding: Friction in global-local encounters. Peacebuilding 1(3): 289-299.

Björkdahl A, Höglund K, Millar G, Van der lijn J and Verkoren W (2016) Peacebuilding and Friction: Global and Local Encounters in Post Conflict Societies. London: Routledge.

Bräuchler B (2015) The Cultural Dimensions of Peace: Decentralization and Reconciliation in Indonesia. Basingstoke: Palgrave MacMillan.

Brett R and Malagon L (2013) Overcoming the original sin of the 'original condition': How reparations may contribute to emancipatory peacebuilding. Human Rights Review 14(3): 257-271.

Call CT and Cousens EM (2008) Ending wars and building peace: International responses to war-torn societies. International Studies Perspectives 9(1): 1-21. 
Chandler D (2013) Peacebuilding and the politics of non-linearity: Rethinking 'hidden' agency and 'resistance'. Peacebuilding 1(1): 17-32.

Chandler D (2006) Empire in Denial: The Politics of State-Building. London: Pluto Press.

Clark JN (2011) UN peacekeeping in the Democratic Republic of Congo: Reflections on MONUSCO and its contradictory mandate. Journal of International Peacekeeping 15(3-4): 363-383.

Coetzee WS (2013) Rethinking the theoretical foundation of the security-development nexus: Does a hybrid complexity-postmodern model contribute? Academic Journal of Interdisciplinary Studies 2(9): 295-303.

Collins B and Watson A (2018) The impetus for peace studies to make a collaborative turn: Towards community collaborative research. In: Millar G (ed) Ethnographic Peace Research: Approaches and Tensions. Basingstoke: Palgrave.

Crewe E and Young J (2002) Bridging Research and Policy: Context, Evidence and Links. ODI Working Paper 173. London: Overseas Development Institute.

De Coning C (2013) Understanding peacebuilding as essentially local. Stability 2(1): 1-6.

Donais T (2012) Peacebuilding and Local Ownership: Post-Conflict Consensus-Building. New York, NY: Routledge.

Donais T (2009) Empowerment or imposition? Dilemmas of local ownership in post-conflict peacebuilding processes. Peace and Change 34(1): 3-26.

Doyle MW (2005) Three pillars of the liberal peace. American Political Science Review 99(3): 463-466.

Elmore RF (1979-80) Backward mapping: Implementation research and policy decisions. Political Science Quarterly 94(4): 601-616.

Engle Merry S and Wood S (2015) Quantification and the paradox of measurement: Translating children's rights in Tanzania. Current Anthropology 56(2): 205-229.

Franks J and Richmond OP (2008) Coopting liberal peace-building: Untying the gordian knot in Kosovo. Cooperation and Conflict 43(1): 81-103.

Goetschel L and Hagmann T (2009) Civilian peacebuilding: Peace by bureaucratic means? Conflict, Security and Development 9(1): 55-73.

Haas PM (1992) Introduction: Epistemic communities and international policy coordination. International Organization 46(1): 1-35.

Helbich WJ (1967-1968) American liberals in the League of Nations controversy. The Public Opinion Quarterly 31(4): 568-596.

Hirsch F (2005) Empire of Nations: Ethnographic Knowledge and the Making of the Soviet Union. Ithaca, NY: Cornell University Press. 
Jackson M (2004) In Sierra Leone. Durham, NC: Duke University Press.

Kappler S and Richmond OP (2011) Peacebuilding and culture in Bosnia and Herzegovina: Resistance or emancipation? Security Dialogue 42(3): 261-278.

Keeley J and Scoones I (1999) Understanding Environmental Policy Processes: A Review. IDS Working Paper 89. Brighton: Institute of Development Studies.

Leonardsson H and Rudd G (2015) The 'local turn' in peacebuilding: A literature review of effective and emancipatory local peacebuilding. Third World Quarterly 36(5): 825-839.

Lindblom CE (1979) Still muddling, not yet through. Public Administration Review 39(6): 517-526.

Mack A (2002) Civil war: Academic research and the policy community. Journal of Peace Research 39(5): 515-525.

Mac Ginty R and Firchow P (2016) Top-down and bottom-up narratives of peace and conflict. Politics 36(3): 308-323.

Mac Ginty R (2011) International Peacebuilding and Local Resistance: Hybrid Forms of Peace. New York: Palgrave MacMillan.

Mac Ginty R (2010) Hybrid peace: The interaction between top-down and bottom-up peace. Security Dialogue 41(4): 391-412.

MacLeod J (2015) Merdeka and the Morning Star: Civil Resistance in West Papua. Brisbane: Queensland University Press.

McGee, R (1997) Ethnography and Rapid Appraisal in Doctoral Research on Poverty. PLA Notes 28: 5558.

Miller JH and Page SE (2011) Complex Adaptive Systems: An Introduction to Computational Models of Social Life. Princeton, NJ: Princeton University Press.

Millar G (2018a) Ethnographic Peace Research: Approaches and Tensions. Basingstoke: Palgrave.

Millar G (2018b) Ethnographic Peace Research: The Underappreciated Benefits of Long-term Fieldwork. International Peacekeeping, DOI: 10.1080/13533312.2017.1421860.

Millar G (2017) For whom do local peace processes function? Maintaining Control through Conflict Management. Cooperation and Conflict 52(3): 293-308.

Millar G (2014a) An Ethnographic Approach to Peacebuilding: Understanding Local Experiences in Transitional States. London: Routledge.

Millar G (2014b) Disaggregated hybridity: Why hybrid institutions do not produce predictable experiences of peace. Journal of Peace Research 51(4): 501-514. 
Millar G (2013) Expectations and experiences of peacebuilding in Sierra Leone: Parallel peacebuilding processes and compound friction," International Peacekeeping 20(2): 193-207.

Millar G (2010) Assessing local experiences of truth-telling in Sierra Leone: Getting to 'why' through a qualitative case study analysis. International Journal of Transitional Justice 4(9): 477-496.

Millar G, van der Lijn J and Verkoren W (2013) Peacebuilding plans and local reconfigurations: Frictions between imported processes and indigenous practices. International Peacekeeping 20(2): 137-143.

Paffenholz T (2015) Unpacking the local turn in peacebuilding: A critical assessment towards on agenda for future research. Third World Quarterly 36(5): 857-874.

Paffenholz T and Reychler L (2005) Towards better policy and programme work in conflict zones: Introducing the 'aid for peace' approach. Journal of Peacebuilding and Development 2(2): 6-23.

Paris R (2011) Ordering the world: Academic research and policymaking on fragile states. International Studies Review 13(1): 58-71.

Paris R (2004) At War's End: Building Peace after Civil Conflict. Cambridge: Cambridge University Press.

Park R (2014) The Reappeared: Argentine Former Political Prisoners. New Brunswick, NJ: Rutgers University Press.

Patomäki H and Wight C (2000) After postpositivism? The promises of critical realism. International Studies Quarterly 44: 213-237.

Pels P and Salemink O (1994) Introduction: Five theses on ethnography as colonial practice. History and Anthropology 8(1-4): 1-34.

Rapoport A (1970) Can peace research be applied? Journal of Conflict Resolution 14(2): 277-286.

Richmond OP (2012) Beyond local ownership in the architecture of international peacebuilding. Ethnopolitics 11(4): 354-375.

Richmond OP (2009) Becoming liberal, unbecoming liberalism: Liberal-local hybridity via the everyday as a response to the paradoxes of liberal peacebuilding. Journal of Intervention and Statebuilding 3(3): 324-344.

Richmond OP (2006) Patterns of peace. Global Society 20(4): 367-394.

Richmond OP and Mitchell A (2011) Peacebuildng and critical forms of agency: From resistance to subsistence. Alternatives 36(4): 326-344.

Robins S (2012) Challenging the therapeutic ethic: A victim-centred evaluation of transitional justice process in Timor-Leste. The International Journal of Transitional Justice 6(1): 83-105.

Russet B (1994) Grasping the Democratic Peace: Principles for a Post-Cold War World. Princeton, NJ: Princeton University Press. 
Selby J (2013) The myth of liberal peace-building. Conflict, Security \& Development 13(1): 57-86.

Sending OJ (2009) Why Peacebuilders Fail to Secure Ownership and be Sensitive to Context. NUPI Working Paper 755.

Shaw R (2007) Memory frictions: Localizing the truth and reconciliation commission in Sierra Leone. International Journal of Transitional Justice 1(2): 183-207.

Shaw R (2005) Rethinking Truth and Reconciliation Commissions: Lessons from Sierra Leone. USIP Report 130.

Shaw R, Waldorf L and Hazan P (2010) Localizing Transitional Justice: Interventions and Priorities after Mass Violence. Stanford, CA: Stanford University Press.

Smith LT (1999) Decolonizing Methodologies: Research and Indigenous Peoples. London: Zed Books.

Sukarieh M and Tannock S (2008) In the best interests of youth or neoliberalism? The World Bank and the new global youth empowerment project. Journal of Youth Studies 11(3): 301-312.

Teethling T (2011) From MONUC to MONUSCO and beyond: Prospects for reconstruction, statebuilding and security governance in the DRC. South African Journal of International Affairs 18(1): 2341.

Theidon K (2013) Intimate Enemies: Violence and Reconciliation in Peru. Philadelpha, PA: University of Pennsylvania Press.

Theissen C (2011) Emancipatory peacebuilding: Critical responses to (neo)liberal trends. In: Matyók T, Senehi J and Byrne S (eds) Critical Issues in Peace and Conflict Studies: Theory, Practice, and Pedagogy. Lanham, MD: Lexington Books, pp. 115-140.

United Nations (2012) Planning Toolkit. New York, NY: United Nations. Available at: http://www.un.org/en/peacekeeping/publications/Planning\%20Toolkit_Web\%20Version.pdf.

Varisco AE (2014) The influence of research and local knowledge on British-led security sector reform policy in Sierra Leone. Conflict, Security and Development 14(1): 89-123.

Webb-Gannon C (2017) Effecting change through peace research in a methodological 'no-man's land': A Case study of West Papua. The Asia Pacific Journal of Anthropology 18(1): 18-35. 